\title{
Neuraminidase Treatment Abrogates the Binding Abnormality of IgA1 from IgA Nephropathy Patients and the Differential Charge Distribution of Its a-Heavy Chains
}

\author{
O.H. Hashima A.S. Shuiba C.T. Chuab \\ Departments of aBiochemistry and ${ }^{\mathrm{b}}$ Medicine, Faculty of Medicine, University of Malaya, Kuala Lumpur, Malaysia
}

\section{Key Words}

$\lg \mathrm{A}$ nephropathy $\cdot \lg \mathrm{A} 1 \cdot$ Sialic acid $\cdot$ Lectin-C $\cdot \alpha$-Heavy chain - Two-dimensional gel electrophoresis

\begin{abstract}
We have studied the interaction of the Gal-GalNAc-reactive champedak lectin- $C$ with neuraminidase-treated and untreated $\lg \mathrm{A} 1$ from $\lg \mathrm{A}$ nephropathy patients. The binding ability of the lectin to untreated $\lg A 1$ from $\lg A$ nephropathy patients was significantly lower as compared to the untreated IgA1 from normal controls. This differential lectin-binding capacity was abrogated when the experiment was performed on neuraminidasetreated sera. Treatment of the serum $\lg A 1$ with neuraminidase also abrogated the differential charge distribution between the $\alpha$-heavy chains of IgA nephropathy patients and normal controls.
\end{abstract}

Copyright $\odot 2001$ S. Karger AG, Basel

\section{Introduction}

The idea that the abnormality of the $O$-glycans of IgA 1 would cause the immunoglobulin deposition in the kidney mesangium of IgA nephropathy (IgAN) patients re- ceives support from numerous experiments. The binding of IgA1 to different cells and tissues is influenced by the structures of the hinge region $O$-linked oligosaccharide moieties. Modification of the structures of the $O$ glycans was demonstrated to cause profound alteration in the binding ability of IgA1 to cells of the liver and kidney [1].

Lectin-binding studies have established the difference between the structures of $O$-linked oligosaccharides of IgA1 between IgAN patients and normal controls. IgA1 from the sera of patients with IgAN displayed a decreased binding to the Gal-GalNAc-reactive jackfruit lectin, jacalin $[2,3]$. The patients' IgA1 was also reported to contain relatively higher asialo-Gal-GalNAc moieties [4]. When the $\alpha$-heavy chains of IgA1 from IgAN patients' sera was analyzed for their charges and compared to that of normal controls, the distribution of charge was found to be significantly higher at the cationic region [5].

In the present study we have investigated the effect of neuraminidase treatment on IgA1 from patients with IgAN, in terms of its interaction with the Gal-GalNAcreactive champedak lectin- $\mathrm{C}$ as well the charge distribution pattern of its $\alpha$-heavy chains.

\begin{tabular}{ll}
\hline KARGER & ( ) 2001 S. Karger AG, Basel \\
Fax +4161306 12 34 & 0028-2766/01/0894-0422\$17.50/0 \\
$\begin{array}{l}\text { E-Mail karger@karger.ch } \\
\text { www.karger.com }\end{array}$ & $\begin{array}{l}\text { Accessible online at: } \\
\text { www.karger.com/journals/nef }\end{array}$
\end{tabular}

\author{
Dr. O.H. Hashim \\ Department of Biochemistry \\ Faculty of Medicine, University of Malaya \\ Kuala Lumpur 50603 (Malaysia)
}

E-Mail onnhashim@medicine.med.um.edu.my 


\section{Materials and Methods}

Sera

Serum samples were obtained from 10 IgAN outpatients (age range 22-58 years) of the University Hospital, Kuala Lumpur, and 10 normal healthy adult volunteers (age range 20-42 years). The subjects came from different ethnic backgrounds (Malay, Chinese and Indian). Neuraminidase treatment of sera was performed at $35^{\circ} \mathrm{C}$ for $24 \mathrm{~h}$ in acetate buffer, pH 5.0, using the enzyme from Vibrio cholerae (Sigma Chemical Co., St. Louis, Mo., USA).

\section{Lectin}

The isolation of lectin-C was performed by subjecting the crude extract of champedak seeds to immobilized galactose-Sepharose affinity chromatography as previously described [5]. Lectin-C was conjugated to horseradish peroxidase (HRP) by incubation of the purified lectin with periodate-activated HRP in sodium carbonate buffer, $\mathrm{pH} 9.5$, for $2 \mathrm{~h}$ at room temperature. The solution was stirred for another $2 \mathrm{~h}$ at $4^{\circ} \mathrm{C}$ upon addition of sodium borohydrate to reduce the remaining free enzymes. The conjugated lectin was kept at $4^{\circ} \mathrm{C}$ in the presence of $60 \%(\mathrm{v} / \mathrm{v})$ glycerol.

\section{Interaction of Champedak Lectin-C with Serum IgA 1}

The wells of the microtiter plate were coated with $0.5 \mu \mathrm{g} / \mathrm{ml}$ antihuman IgA in phosphate-buffered saline (PBS) with $0.5 \%$ Tween-20 for $18 \mathrm{~h}$ at $4{ }^{\circ} \mathrm{C}$. The wells were subsequently blocked with $1 \%(\mathrm{w} / \mathrm{v})$ bovine serum albumin in PBS for $1 \mathrm{~h}$ at $4^{\circ} \mathrm{C}$. Serum samples, with their IgA concentrations standardized to $40 \mu \mathrm{g} / \mathrm{ml}$, were added to the wells and incubated at room temperature for $2 \mathrm{~h}$. The interaction between serum IgA1 with champedak lectin-C was tested by addition of optimal concentration of the enzyme-conjugated lectin, determined based on the results of a chequered-board ELISA. For color development, $0.04 \%(\mathrm{w} / \mathrm{v}) o$-phenylenediamine and $0.008 \%(\mathrm{v} / \mathrm{v})$ $\mathrm{H}_{2} \mathrm{O}_{2}$ in phosphate-citrate buffer were added. The plate was incubated at room temperature in the dark for $15 \mathrm{~min}$. The reaction was stopped by addition of $3 \mathrm{M} \mathrm{HCl}$. The plate was read at $492 \mathrm{~nm}$ by using the ELISA reader.

\section{Analysis of the Charge Distribution Ratio of Asialo- $\alpha$-Heavy Chains}

To determine the charge distribution of neuraminidase-treated $\alpha$-heavy chains of IgAN patients and normal controls, we have adopted a previously described experimental strategy [5]. The method involved separation of sera by two-dimensional (2-D) gel electrophoresis, their transfer onto nitrocellulose membrane and the detection of the asialo- $\alpha$-heavy chain band by using HRP-conjugated champedak lectin-C. Position of the asialo- $\alpha$-heavy chan band was initially detected using enzyme-conjugated anti-human IgA1 (Binding Site, Birmingham, UK). Distribution of the specific regions of the $\alpha$-heavy chain band was analyzed in terms of volume, i.e., optical density $x$ area in square millimeters of region performed by using the computerized Molecular Analyst densitometry software (Bio-Rad, Hercules, Calif., USA) subsequent to an automated background optical density subtraction.

\section{Statistical Analysis}

All values are presented as mean \pm SD. The Mann-Whitney Utest was used to analyze the significant differences between normal subjects and patients. A p value $<0.05$ was considered significant.

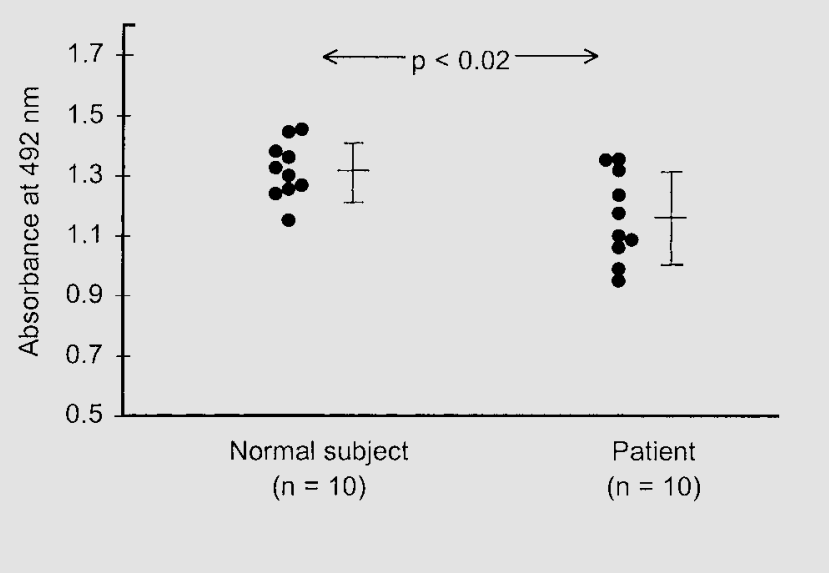

Fig. 1. Interaction of champedak seed lectin-C with serum IgA1. Serum samples were initially standardized for IgA concentration at $40 \mu \mathrm{g} / \mathrm{ml}$. The sera were incubated in a microtiter plate coated with anti-IgA, in triplicate. The $O$-glycan moieties in the retained IgA1 were detected with HRP-conjugated lectin-C at $0.06 \mu \mathrm{g} / \mathrm{ml}$.

\section{Results}

\section{Interaction of Lectin-C with Neuraminidase-Treated and Untreated Serum IgAI}

In this study, the interaction of champedak lectin-C with standardized concentrations of serum IgA1 of normal controls and IgAN patients was initially investigated. The average absorbance reading for IgAN patients was significantly lower $(1.146 \pm 0.146)$ as compared to that of normal subjects $(1.320 \pm 0.095)$ (fig. 1$)$. When the experiment was repeated using neuraminidase-treated sera, the difference between the values obtained from patients and normal controls was no longer significant (fig. 2). The average absorbance readings for normal subjects and patients with $\mathrm{IgAN}$ were $0.750 \pm 0.093$ and $0.749 \pm$ 0.090, respectively.

\section{Charge Distribution of Neuraminidase-Treated $\alpha$-Heavy Chains}

The anionic:cationic region distribution ratio of the asialo- $\alpha$-heavy chains of IgA1 from IgAN patients and normal controls was determined by subjecting neuraminidase-treated serum samples to an analytical strategy as described in our previous report [5]. Neuraminidase treatment had apparently shifted the position of the asialo- $\alpha$ heavy chain spots to the positive side of the 2-D gel. When the distribution of charge of the asialo- $\alpha$-heavy chains of IgA1 was analyzed by using the $\mathrm{p} I$ of 5.6 as a midpoint as 


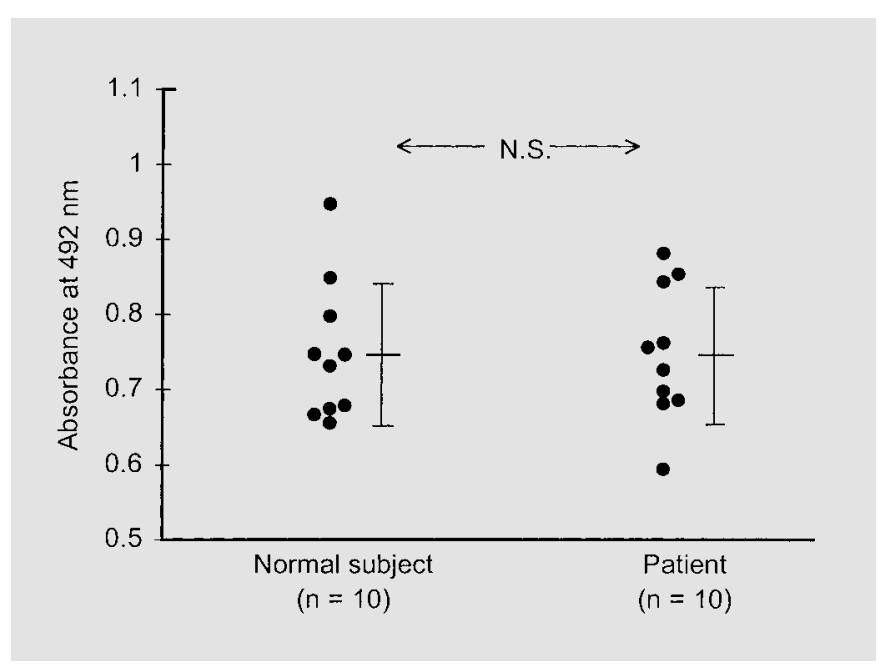

Fig. 2. Interaction of champedak seed lectin- $\mathrm{C}$ with neuraminidasetreated serum IgA1. Serum samples were treated with neuraminidase from $V$. cholerae for $24 \mathrm{~h}$ at $35^{\circ} \mathrm{C}$ in acetate buffer, $\mathrm{pH}$ 5.0. The binding study was performed in the same manner as described in the legend of figure 1 .

adopted by previously described methods [5-7], there was no significant difference between the anionic-cationic ratio obtained for the IgAN patients $(0.148 \pm 0.088)$ and that of normal controls $(0.155 \pm 0.058)$ (fig. 3$)$.

\section{Discussion}

Champedak lectin- $\mathrm{C}$ is a plant lectin that binds to the $O$-glycans of IgA1 similar to jacalin $[8,9]$. In this study, we have demonstrated that the affinity of the champedak lectin-C to serum IgA1 was significantly weaker in patients with IgAN as compared to normal controls. Our data are compatible with the earlier reports of Andre et al. [2] and Mestecky et al. [3] using jacalin. The decreased binding of the IgA1 from IgAN patients to the Gal-GalNAc-reactive champedak lectin-C implies that the $O$-glycans of the immunoglobulins were generally lacking in Gal residues, either exclusively or with sialic acid residues. When the lectin-binding assay was repeated using neuraminidase-treated sera, the differential binding ability between the asialo-IgA1 from IgAN patients and normal controls was no longer significant. The data indicate that sialic acid residues provide significant contribution to the affinity difference of champedak lectin- $\mathrm{C}$ binding to the $O$-glycans of IgA1 between patients and normal controls.

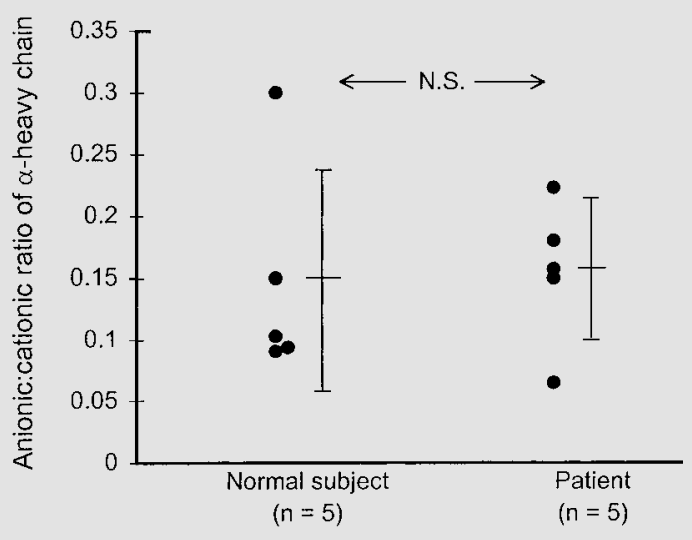

Fig. 3. Mean anionic:cationic ratio of the total asialo- $\alpha$-heavy chain band from normal healthy controls and IgAN patients. The 2-D separated $\alpha$-heavy chain band of neuraminidase-treated IgA1 was detected by using enzyme-conjugated champedak lectin-C. A p $I$ of 5.6 was used to divide the band into its anionic $(\mathrm{p} I<5.6)$ and cationic regions $(\mathrm{p} I>5.6)$ according to previously adopted methods [5-7]. There was no significant difference between the mean ratio of volume distribution of anionic:cationic regions of the asialo- $\alpha$-heavy chains from normal controls $(0.148 \pm 0.088)$ and IgAN patients $(0.155 \pm 0.058)$.

In our previous report, we have demonstrated that the $\alpha$-heavy chains of IgAN patients were generally more cationic as compared to the $\alpha$-heavy chains of normal healthy controls [5]. In this study, we have extended the previous investigation by repeating the experiments using neuraminidase-treated sera. Our data demonstrate that the distribution of charge of the asialo- $\alpha$-heavy chains of IgA1 was not significantly different between the IgAN patients and normal healthy controls. The abrogation of the differential charge distribution of the $\alpha$-heavy chains between patients and normal controls by neuraminidase treatment provides direct evidence for the differences in the quantity of their sialic acid residues.

Taken together, the data of our present study indicate that the binding abnormality of IgA1 from IgAN patients and the differential charge distribution of its $\alpha$-heavy chains are attributed to the differences in their sialic acid residue content. This is in agreement with the report of Hiki et al. [4] which demonstrated that the hinge-region IgA1 of IgAN patients contained a relatively higher concentration of asialo-Gal-GalNAc moieties when compared with control IgA1. The lower degree of IgA1 sialylation may be due to the effects of elevated levels of IL-4 
and IL-5 in the IgAN patients [10]. A deficiency of sialic acid residues may induce a conformational instability to the IgA1 molecule. IgA1 low in sialic acid residues has been shown to have profiles similar to the heat-labile IgA1 [11]. The abnormalities of the hinge-region $O$-glycans may result in autoaggregation in a similar manner to the IgG molecules in rheumatoid arthritis [12].

\section{Acknowledgement}

This work was supported by IRPA research grant 06-02-03-0563 from the Ministry of Science, Technology and Environment of Malaysia.

\section{References}

1 Mestecky J, Hashim OH, Tomana M: Alterations in the IgA carbohydrate chains influence the cellular distribution of IgA1; in Clarkson AR, Woodroffe AJ (eds): IgA Nephropathy: Pathogenesis and Treatment. 6th International Symposium on IgA Nephropathy, Adelaide 1994. Contrib Nephrol. Basel, Karger, 1995, vol 111, pp 66-72.

2 Andre PM, Le Pogamp P, Chevet D: Impairment of jacalin binding to serum $\operatorname{IgA}$ in $\operatorname{IgA}$ nephropathy. J Clin Lab Anal 1990;4:115119.

3 Mestecky J, Tomana M, Crowley-Nowick PA, Moldoveanu Z, Julian BA, Jackson S: Defective galactosylation and clearance of IgA 1 molecules as a possible etiopathogenic factor in IgA nephropathy; in Bene MC, Faure M, Kessler M (eds): IgA Nephropathy: The 25th Year International Symposium, Nancy 1992. Contrib Nephrol. Basel, Karger, 1993, vol 104, pp 172182.
4 Hiki Y, Iwase H, Kokubo T, Horii A, Tanaka A, Nishikido J, Hotta K, Kobayashi Y: Association of asialo-galactosyl- $\beta 1,3-N$-acetylgalactosamine on the hinge with a conformational instability of jacalin-reactive immunoglobulin A1 in immunoglobulin A nephropathy. J Am Soc Nephrol 1996;7:955-960.

5 Shuib AS, Chua CT, Hashim OH: Sera of IgA nephropathy patients contain a heterogeneous population of relatively cationic alpha-heavy chains. Nephron 1998;78:290-295.

6 Lai KN, Chui SH, Lewis WHP, Poon ASY, Lam CWK: Charge distribution of IgA-lambda in IgA nephropathy. Nephron 1994;66:38-44.

7 Monteiro RC, Halbwachs-Mecarelli L, RoqueBarreira MC, Noel L, Berger J, Lesavre P: Charge and size of mesangial IgA in IgA nephropathy. Kidney Int 1985;28:666-671.

8 Hashim OH, Ng CL, Gendeh GS, Nik Jaafar MI: IgA binding lectins isolated from distinct Artocarpus species demonstrate differential specificity. Mol Immunol 1991;28:393-398.
9 Hashim OH, Gendeh GS, Nik-Jaafar MI: Comparative analyses of IgA1 binding lectins from seeds of six distinct clones of Artocarpus integer. Biochem Mol Biol Int 1993;29:69-76.

10 Chintalacharuvu SR, Emancipator SN: The glycosylation of $\operatorname{IgA}$ produced by murine $\mathrm{B}$ cells is altered by $\mathrm{Th} 2$ cytokines. J Immunol 1997; 159:2327-2333.

11 Iwase H, Tanaka A, Hiki Y, Kokubo T, IshiiKarakasa I, Kobayashi Y, Hotta K: Abundance of Gal $\beta 1,3 \mathrm{GalNAc}$ in O-linked oligosaccharide on hinge region of polymerized IgA1 and heataggregated IgA1 from normal human serum. J Biochem 1996;120:92-97.

12 Parekh RB, Dwek RA, Sutton BJ, Fernandes DL, Leung A, Stanworth D, Rademacher TW, Mizuochi T, Miyamoto T, Kobata A: Association of rheumatoid arthritis and primary osteoarthritis with changes in the glycosylation pattern of total serum IgG. Nature 1985;316: 452-457. 